\section{In vitro measurements of compression bandages and bandage systems: a review of existing methods and recommendations for improvement}

\section{Jan Schuren \\ Retired from 3M Deutschland $\mathbf{G m b H}$, Skin and Wound Care Division, Neuss, Germany}

\section{Abstract}

In this article an overview is presented of identified devices that are or can be used for in vitro pressure and stiffness measurements of compression bandages and bandage systems. The performance of these devices has been evaluated on several parameters as well as the clinical relevance of the findings. In addition, recommendations for improvement and standardization of future measurements from the International Compression Club (ICC) working group compression bandages are presented.

\section{Introduction}

There is a variety of methods to describe the properties of bandages used for a variety of indications where compression therapy is required. Often the extensibility of materials is used to determine their characteristics. The German DIN quality standard (Deutsches Institut für Normung EV) ${ }^{1}$ defines the elasticity of bandages by percent elongation following the application of a force of $10 \mathrm{~N}$ per $\mathrm{cm}$ bandage width. The resulting maximal stretch percentage divides bandages in three categories: i) rigid (0-10\%); ii) short stretch (10-100\%); and iii) long stretch (>100\%). Veraart et al. ${ }^{2}$ present four categories: i) non-elastic; ii) short-stretch ( $<70 \%$ maximal tension); iii) medium stretch (70-140\%); and iv) fully elastic (>140\%). Thomas $^{3}$ classifies bandages into three distinct types which have fairly precise clinical indications. They are retention (class 1), light support (class 2) and the provision of varying degrees of compression (classes 3a-3d). These compression bandages are subdivided into four groups according to their ability to retain predetermined levels of tension under controlled laboratory conditions. It is this tension which governs the pressure that the various products might be expected to apply in use. Thomas also recognizes that there are certain other highly special- ized products available which may not fit into this classification and these should therefore be considered separately.

The International Compression Club (ICC; http://www.icc-compressionclub.com/) held a consensus meeting in 2005 on measurements of lower leg compression in vivo and published their recommendations, in which was stated that sub-bandage pressures and material stiffness characterize the elastic properties of the used materials and are the deciding parameters determining the dosage of compression treatment. ${ }^{4}$ Partsch describes the method to measure the pressure at a defined position of the lower leg at rest and to repeat the measurement on the same spot, when the circumference has maximally increased by the muscles actively engaged to stand in the upright position. The pressure in the supine position is subtracted from the pressure in stance. The resulting index indicates the effectiveness of the applied system. This index is referred to as static stiffness index (SSI) and provides an indication of how well an applied compression system manages to keep forces produced by the muscle activity to stay in the upright position, inside the compressed area. ${ }^{5}$ Provided that they are applied with the same resting pressure, typically short stretch bandages have higher SSI's than long stretch bandages.

Following a subsequent ICC meeting, another consensus document was published in which the growing trend is mentioned for the use of both multilayer bandages and bandage kits that consist of several bandaging materials, which influence sub-bandage pressure and stiffness. It is stated that it is not possible to use in vitro data to predict the influence of these parameters and therefore they need to be measured on the leg. ${ }^{6}$ Mosti et al. state that the physical characteristics of bandage kits, in which different materials are combined, cannot be predicted by laboratory tests and can only be assessed in vivo by measuring the interface pressure and calculation of stiffness. ${ }^{7}$ Schuren et al. conclude that although the well-established SSI in general is able to differentiate between elastic and inelastic materials, it only provides a rough estimate of the effectiveness of applied systems as interpretation is heavily influenced by the muscle forces of the person being bandaged. ${ }^{8}$

Besides the mentioned variation caused by variability from the human leg, which cannot be standardized, there is the variation caused by the person applying the system. The application of bandage systems by experienced nurses to volunteers ${ }^{9}$ or on artificial legs $s^{10}$ shows a marked variation in applied pressure. The consequence is that making statements on the possible effectiveness of an applied system, is difficult.

Medical elastic compression stockings (MECS) can be divided into different classes
Correspondence: Jan Schuren, Grotestraat 34 6067 BR Linne, The Netherlands.

E-mail: jan.schuren@gmail.com

Key words: compression therapy, bandages, bandage systems, in vitro measurements, pressure, static stiffness index, strain index.

Conflicts of interest: JS is a retired 3M employee and invented and co-developed the 3M Coban 2 Layer compression systems.

Members of the International Compression Club (ICC) working group bandages who agreed with this consensus document: Abel M. (Germany), Bender D. (USA), Besse B. (Germany), Bichel J. (Germany), Charles H. (UK), Convert R. (France), Damstra RJ. (The Netherlands), Hitschman G. (Germany), Kloeppels M. (Germany), Mooij M. (The Netherlands), Morrison T. (USA), Mosti G. (Italy), Muldoon J. (UK), Partsch H. (Austria), Planisek Rucigaj T. (Slovenia), Polpot S. (France), Schuren J. (The Netherlands), Schwidden I. (Germany), Will K. (Germany).

Received for publication: 5 November 2013.

Revision received: 27 May 2014.

Accepted for publication: 28 May 2014

This work is licensed under a Creative Commons Attribution 3.0 License (by-nc 3.0).

○C Copyright J. Schuren, 2014

Licensee PAGEPress, Italy

Veins and Lymphatics 2014; 3:2107

doi:10.4081/vl.2014.2107

based on pressure. However, pressure is not the only parameter that differentiates one stocking from another. Just as for compression bandages, the so-called stiffness factor, the elasticity coefficient or slope value of the stocking is another important parameter. This slope value is defined as the increase in pressure when the circumference of the stocking increases by $1 \mathrm{~cm}$. This slope value is determined in the laboratory. ${ }^{11}$ Neumann states that it is not sufficient to determine the compression (class) of the MECS alone, also the stiffness or elasticity coefficient is of importance for the final results of compression therapy. He provides objective criteria for prescribing MECS for venous diseases in phlebology. ${ }^{12}$

Currently many different bandage systems are commercially available. They all include instructions for their most optimal use. It is obvious that with so many available compression bandages and systems, there is a need to have a method that exactly determines the properties of an applied system and eventual modifications. ${ }^{13}$ Two decades ago, McCollum identified the need to ensure that prescribable bandages meet acceptable standards of manufacture and specified performance in terms of elasticity, elastic range, elastic modulus, and 
durability and suggested to lay down these criteria and classify bandages according to some measure of elasticity and elastic modulus. ${ }^{14}$ Clark states that simplistic descriptions of short-stretch and long-stretch bandages fail to take account of the huge variations within these two groups and, more importantly, the development of multi-layer compression systems that combine materials with different performance characteristics. He concludes that the current classification system refers to individual bandages and does not adequately reflect the physiological effects of multi-layer bandaging systems and that a European-wide standard for the testing and classification of bandage systems is required. ${ }^{15}$

Schuren developed and validated a method to measure under completely controlled conditions the capabilities of an applied compression system to keep the forces inside the system, similar to the SSI. As the name SSI is well established, a different description was needed for the value from this measurement and the term strain index was selected. ${ }^{13}$ In a recent document, Cornu-Thenard et al. propose that the term resistance should be used in the medical compression vocabulary or that perhaps words similar to resistance or resistance coefficient could be used such as hardness, rigidity, firmness, inelasticity and others. ${ }^{16}$

As in vitro measurements can be performed over a longer period, also the effects of material fatigue on pressure and stiffness can be investigated.

In an overview to highlight the differences between different compression materials, Clark states that if the main in vitro and in vivo comparisons are to remain pressure and force measurement bound, then there is a need for a consistent classification system based upon the pressure measurements to mirror the agreed consensus upon how subbandage pressures are to be measured. ${ }^{17}$

Figure 1 shows an overview of evaluations that can be performed on compression bandages and bandage systems, with the specific role for in vitro and in vivo research.

In this article an overview is presented of identified devices that are or can be used for in vitro pressure and stiffness measurements of compression bandages and bandage systems. The performance of these devices has been evaluated on several parameters as well as the clinical relevance of the findings. In addition, recommendations for improvement and standardization of future measurements from the ICC working group compression bandages are presented.

\section{Materials and Methods}

A search in the medical literature was performed in the personal database (Papers
2.2.10; mekentosj.com) and using Medline. Next an extensive manual search was carried out in the bibliographies of identified articles. The search was focused on identifying all available methods that could be used for in vitro pressure and stiffness measurements of compression bandages and/or compression bandage systems (JS). There were no restrictions on quality of identified papers. Next, a patent search was performed using the United States Patent and Trademark Office (http://patft.uspto.gov) and the European Patent Office (www.epo.org) and identified patents were downloaded (JS). A questionnaire was developed with key questions on the method and presented in Table 1.

If the identified published information was sufficient to answer these questions, the questionnaire was completed (JS). If this was not the case, the identified researchers were contacted with the request to provide additional information or to complete the questionnaire. The search ended on May 1, 2013. The results were presented at a meeting of the ICC working group bandages in Copenhagen on May 18, 2013 (JS) for further discussion.

\section{Results}

A total of seventeen devices were identified, nine of them were disclosed in the published literature, six were found in patent applications and two were brought in by members of the ICC working group bandages, who used them in their commercial working environment. The oldest identified device was disclosed in a patent application from 1979, the last came from a publication from 2012. An overview of the devices is listed on date of publication, either in literature or on date of patent application and is presented in Table $2 .^{13,18-30}$ Several devices are published in more than one publication; the one that describes the device in the highest detail is listed in the overview.

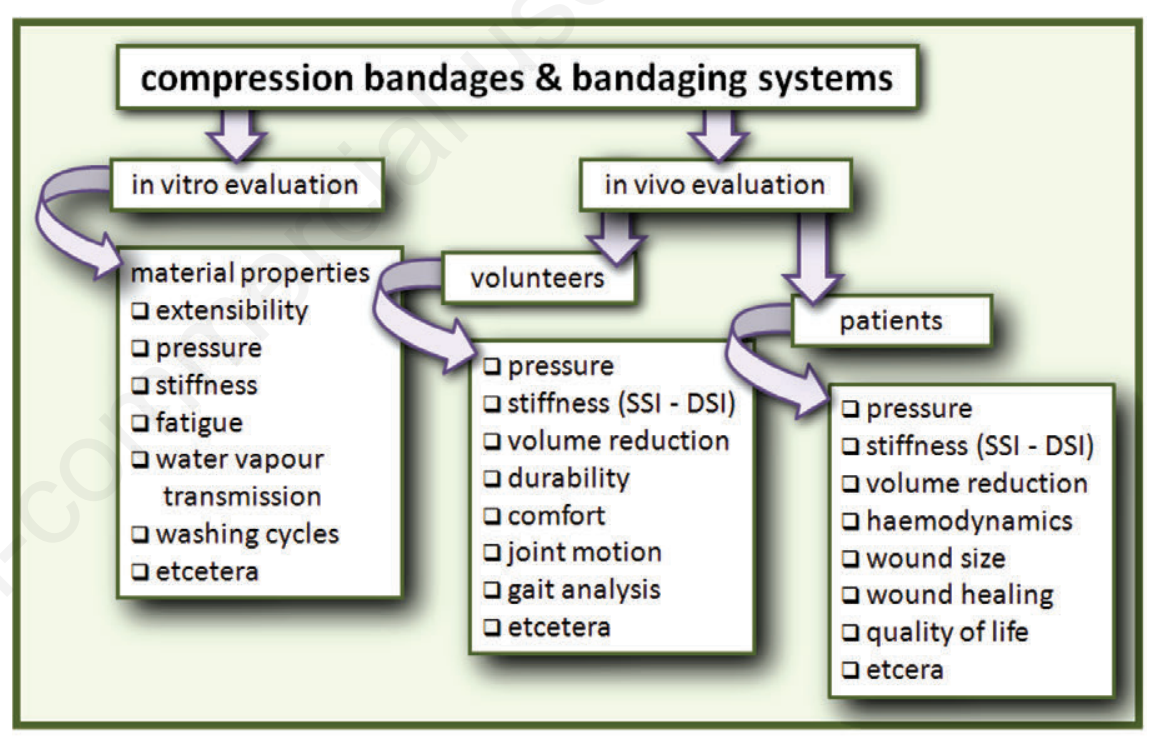

Figure 1. Evaluation methods on compression bandages and bandage systems.

Table 1. Questionnaire with the key questions.

\begin{tabular}{l} 
Name of the device: \\
Resting pressure $(\mathrm{y} / \mathrm{n}):$ \\
\hline Stiffness $(\mathrm{y} / \mathrm{n}):$
\end{tabular}


After completion of the questionnaires, the collected information was transferred to a sheet in which each yes from the questionnaire was marked in green and each no in red. This sheet is presented in Figure 2.

\section{Discussion}

For compression bandages and bandaging systems, there is a variety of methods to look at their physical properties. Measuring pressure and stiffness are only a few and In this article, only a minor number of studies describing them are referenced. The ICC has published a consensus document on how the sub-bandage pressure can be measured ${ }^{4}$ and a document on the classification of bandages. ${ }^{6}$ For a variety of reasons, in vitro measurements have also been widely used, not only for stockings but also for bandages.

For in vitro measurements of bandages and bandage systems for compression therapy, it is important that not only the pressure can be identified but also that information can be collected on the stiffness, a measure of the possible performance. Ten of the seventeen identified devices fulfill that requirement. Another important factor for in vitro measurements is that the used method is completely controlled and therefore reproducible. This implies that the application must be automated. For most of the identified systems, bandages have to be applied manually, which reduces the reproducibility. Six identified devices use various automated applications. Combining the positives on stiffness and automated application, leaves only two devices with a green for both parameters. One of them is still under design, which means that only one device (number 13 , Figure 3) has a complete green scorecard.

When bandages or systems are applied with this winder, the force needed to bring each individual component to the required percentage stretch, is calculated on a tensile tester (e.g. 50\% for Profore layer 3; Smith \& Nephew Corp., London, UK). From this force, the weight is calculated with which each individual component of a system must be stretched with the exact amount of tension. Water filled bottles are used of which the weight is controlled with 0.01 grams of precision on a calibrated scale. As can be seen on Figure 3, pressure is measured with a PicoPress ${ }^{\circledR}$ [Microlab Elettronica SAS, Ponte S. Nicolò (PD), Italy] sensor and the data can be stored on a computer. The sensor is positioned on a fluid bag. The stiffness of a system can be measured by inflating another sensor underneath the fluid bag with a controlled amount of air.

An example of a pressure recording with the above described roll winder is shown in the upper measurement in Figure 4. ${ }^{13,31}$
However, many other identified devices have unique design features that could eventually be used to develop an optimal in vitro measuring device. E.g., where device number 16 from Figure 3 only uses the small area of the fluid bag to imitate muscle enlargement, the mannequin leg developed by Hirai et al. ${ }^{31}$ (device number 14, Figure 5), uses the entire area of the leg to enlarge. This may have several advantages, of which probably the most important that this total enlargement reflects the natural situation in a more realistic way.

The ICC working group bandages discussed the findings of the review in a meeting held on May 182013 in Copenhagen. In this and two subsequent meetings held in Germany, the group agreed on a number of recommendations for in vitro measurements of com- pression bandages and bandage systems. These recommendations are listed in Table 3. An overview of the discussed topics is provided below.

\section{Leg-shaped model or cylinder?}

An important question for in vitro measurements of bandages and bandage systems is if the model on which the measurements are to be made, should have a leg-shape or if it can be a cylinder. Twelve of the seventeen identified devices use a leg model, of which only one allows an automated application. The advantage of a cylinder is that not only exactly the number of layers can be applied that is recommended by the manufacturer but also the force of application can be evenly distributed over the entire width of the roll. The

Table 2. An overview of the identified devices.

\begin{tabular}{|c|c|c|}
\hline No. & Name of device & Disclosed in \\
\hline 1 & Hosiery testing apparatus & Swallow ${ }^{18}$ \\
\hline 2 & Measuring apparatus & Wray et al..$^{19}$ \\
\hline 3 & Hosiery pressure measuring device & Pirlitescu et al. ${ }^{20}$ \\
\hline 4 & Pressure measuring device & Testud et al..$^{21}$ \\
\hline 5 & Cylindrical limb model & Melhuish et al. ${ }^{22}$ \\
\hline 6 & Wooden leg & Partsch et al..$^{23}$ \\
\hline 7 & Mannequin leg & Rajendran et al. ${ }^{24}$ \\
\hline 8 & Leg garment test apparatus & Kuenzli et al. ${ }^{25}$ \\
\hline 9 & Mannequin leg & Ghosh et al. ${ }^{26}$ \\
\hline 10 & Elastically deformable limb & Wesp et al. ${ }^{27}$ \\
\hline 11 & Test rig & Al Khaburi28 \\
\hline 12 & Mannequin leg & Schuren $^{13}$ \\
\hline 13 & Roll winder & Schuren $^{13}$ \\
\hline 14 & Mannequin leg & Hirai et al. ${ }^{29}$ \\
\hline 15 & Air bladder mannequin leg & Kumar et al..$^{30}$ \\
\hline 16 & Wrapping unit & $\begin{array}{l}\text { Not disclosed; concept of Karl Otto Braun GmbH \& Co. } \\
\text { KG, Wolfstein, Germany }\end{array}$ \\
\hline 17 & Compression model leg & $\begin{array}{l}\text { Not disclosed; used by Lohmann \& Rauscher GmbH \& Co. } \\
\text { KG, Rengsdorf, Germany }\end{array}$ \\
\hline
\end{tabular}

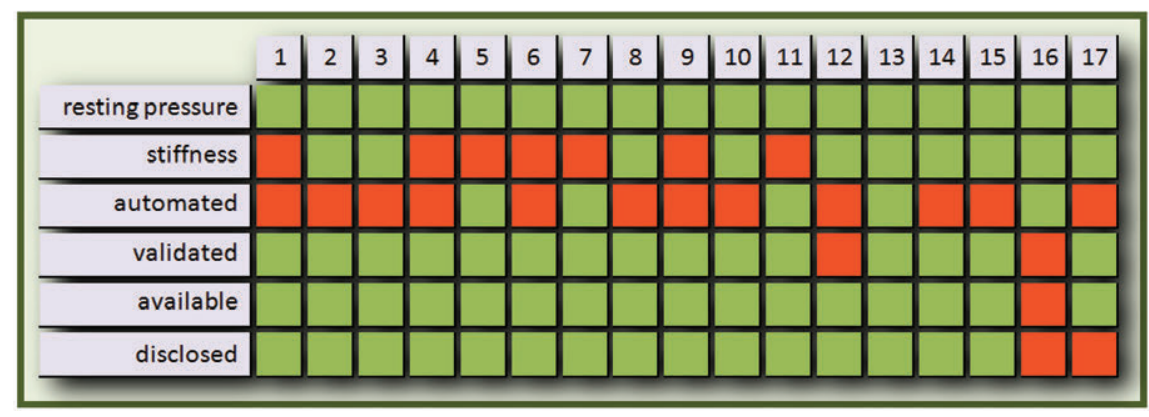

Figure 2. The score card with the 17 devices; each green cell indicates a yes, each red cell a no. 
recommendation of the ICC working group is that for in vitro testing of compression bandages and bandage systems, cylinders should be used. Concerning the material that cylinders are made of, the ICC working group recommends that the friction between cylinder surface and bandaging material should be reduced to the minimal (e.g. by using polished steel).

\section{Application method}

If in vitro pressure measurements are performed on leg-shaped models, it is difficult to have an automated application. This is not a surprising result as most of the reviewed devices were developed to perform measurements on stockings and one to perform research on the reproducibility of pressure and stiffness (device 12). The one leg model which has an application that is described as automatically (device 7), uses a manual winder to turn the fixed leg. ${ }^{29}$ Although it is possible with this device to apply bandages with e.g. a $50 \%$ overlap, it is difficult to have the forces distributed evenly because of the irregularly shaped leg. The recommendation of the ICC working group is that for in vitro testing of compression bandages and bandage systems, the application should be performed as recommended in the instructions for use. In addition, it is recommended that applications should be controlled, automated and reproducible.

\section{Stiffness}

As mentioned, an in vitro assessment of stiffness of compression bandages and especially of bandage systems, the model needs a controlled and reproducible method to imitate the real life situation of measuring the SSI, the difference between the pressure in the supine and upright position. To achieve this enlargement, the mannequin leg (device 14) is cut in half lengthwise and when the lever arm is pushed down, the leg splits by $0.5 \mathrm{~cm}$, leading to a $1 \mathrm{~cm}$ increase in circumference. This method of enlargement guarantees an easy and reproducible method. An example of a pressure recording with the above described mannequin leg is shown in the lower measurement in Figure 3. Ten of the seventeen devices allow stiffness recordings and use different methods of enlargement to achieve these measurements. An increase of $1 \mathrm{~cm}$ over the entire area used in four of them (devices 14, 15,16 and 17). Stolk et al. measured the maximum difference between the maximal dorsiflexion and maximal plantar flexion circumference at the point where the gastrocnemius muscle passes over into its aponeurosis (the so-called B1 point) in five volunteers and found a mean difference of $1.18 \mathrm{~cm} .^{32}$ Enlarging with $1 \mathrm{~cm}$ is arbitrary but based on the findings of Stolk et al., a value that reflects a real-life situation. A $1 \mathrm{~cm}$ increase in circumference also correlates with the stiffness measurements of elastic stockings, which is defined by the European Committee for Standardization (CEN) as the increase in pressure per $1 \mathrm{~cm}$ increase in leg circumference. ${ }^{33}$ The recommendation of the ICC working group is that for in vitro testing of compression bandages and bandage systems, stiffness measurements should be in line with existing methods like the CEN method. As mentioned in the introduction, the name $S S I$ is well established and recommended to be used for in vivo measurements. ${ }^{4,5}$ The recommendation of the ICC working group is that stiffness measured in vitro should not be named static stiffness index. For stockings, the term dynamic index is used. For bandages and bandage systems, a new term e.g. strain index $x^{8,13}$ or in vitro statical stiffness index could be introduced.

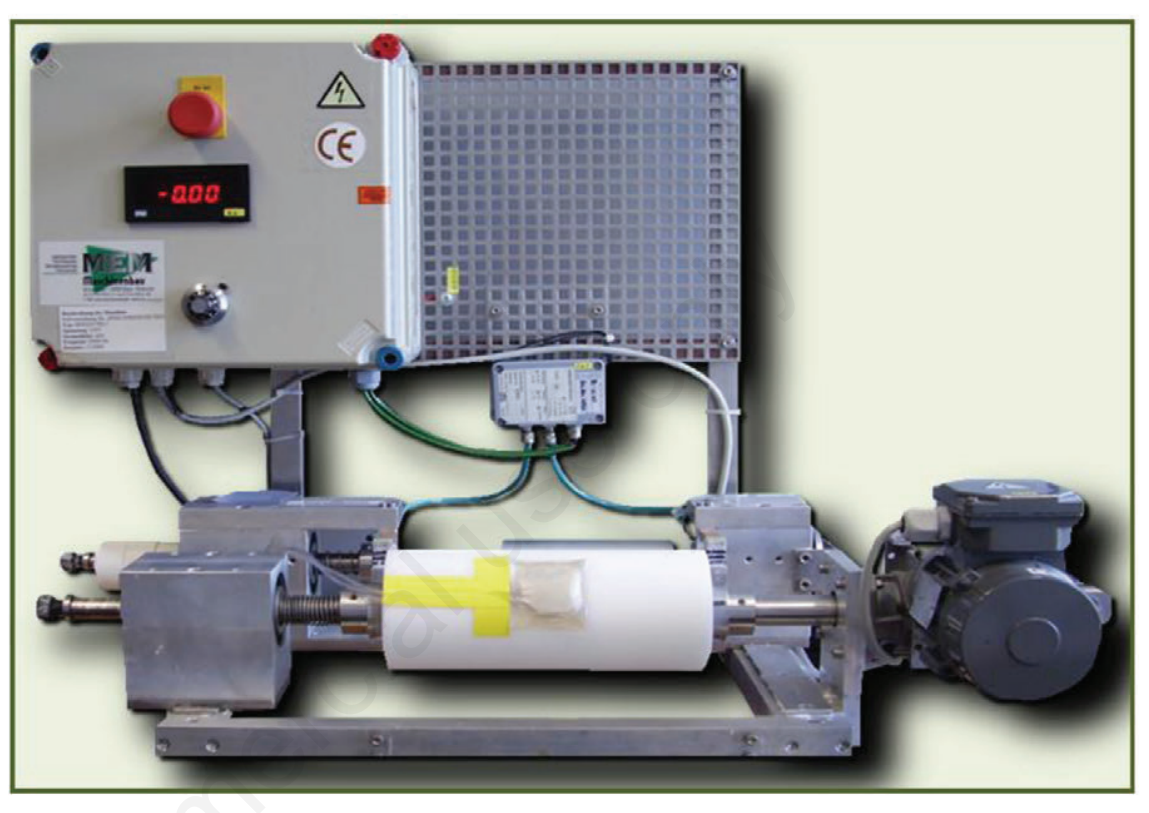

Figure 3. The automated roll winder (device number 13$)$.

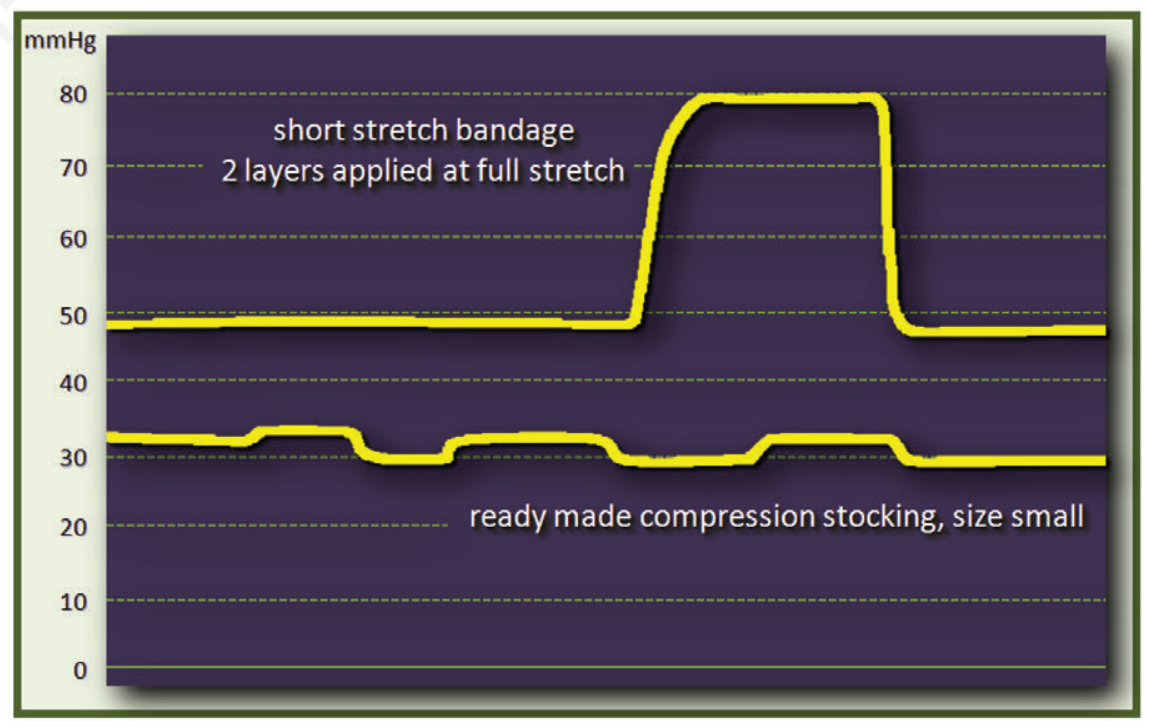

Figure 4. In vitro pressure and stiffness recordings with device number 13 (upper line) and device 14 (lower line); the picture is composed with data from Schuren ${ }^{13}$ and Hirai et al. ${ }^{31}$ which in the original publications are presented on a different scale. 


\section{Radius/circumference of the cylinder}

On four of the seventeen identified devices in this review, cylinders are used to perform the measurements. Following Laplace's law, the final pressure of an application depends on the tension with which the bandage is applied as well as the radius of the cylinder to which it is applied. The six identified devices use different radii with an average radius of $4.7 \mathrm{~cm}$ (range 4.0 to 6.1), which is an average circumference of $29.3 \mathrm{~cm}$. Schuren used cylinders with a radius of 4 and $5 \mathrm{~cm}$ (circumference 25.1 and $31.4 \mathrm{~cm}$ ). In the test method validation, four different operators applied four different compression systems on both cylinders. ${ }^{13}$ The test results reveal that the pressures on the cylinders with the radius of $5 \mathrm{~cm}$, are close to the expected range of pressures when these systems are used in clinical practice. However, further unpublished research of one of the group members revealed that if the method of enlargement described by Hirai $e t$ $a .^{29,31}$ is used on cylinders, a diameter of $4 \mathrm{~cm}$ is closer to the expected range. ${ }^{34}$ Based on these findings, the recommendation of the ICC working group is that for in vitro testing of compression bandages and bandage systems, cylinders should be used with a radius of $4 \mathrm{~cm}$ (circumference $25.1 \mathrm{~cm}$ ).

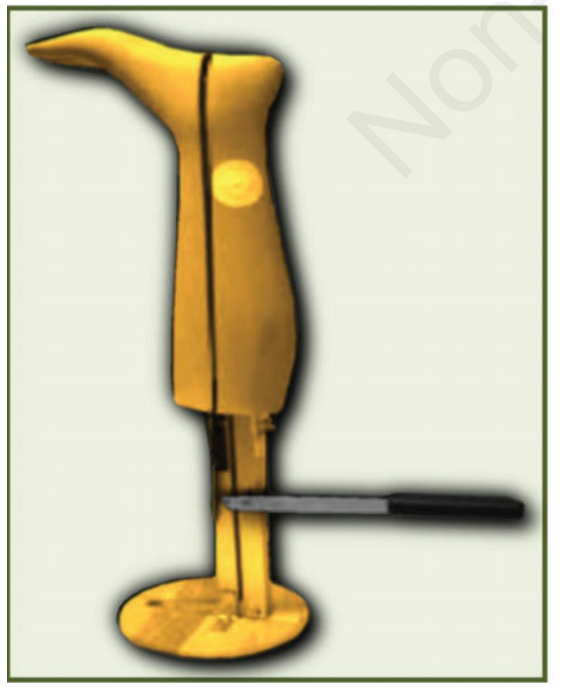

Figure 5. The mannequin lag with the lever arm, which when pushed down, guarantees a $1 \mathrm{~cm}$ enlargement in circumference (device number 14).

\section{Fatigue}

To have an objective measurement of the degree and duration of the compression exerted by six commonly used elastic bandages, Tenman et al. tested the sustainability of pressure on healthy volunteers. ${ }^{35}$ They found pressure drops up to $63 \%$ in $4 \mathrm{~h}$. Partsch reports that when bandages with a high stiffness are applied, a pressure drop will occur in the first minutes and hours when the patient is walking to values that are $30-40 \%$ lower compared to the initial pressure. He states that this drop is mainly due to an immediate reduction of leg volume and that for the next few days only a mild further pressure drop occurs. ${ }^{36}$ Provided that an applied system stays in place, observed pressure drops may be caused by a combination of edema reduction and material fatigue. When loss of pressure is measured on volunteers, it is impossible to identify which of the two components contributes for which part. By profiling the pressure of compression bandages by a computerized instrument, Das et al. showed that in bandages with higher mass per unit area, the internal pressure applied by the bandage decreases at a higher rate than in bandages with lower mass per unit are. In addition, the authors showed that the internal pressure profile with time is different for different bandages, higher internal pressures show a higher rate of pressure loss over time..$^{37}$ This implies that material fatigue and resulting pressure loss could have an effect on pressure but also on stiffness and therefore on the effectiveness of applied systems over time. Schuren studied material properties in vivo on healthy volunteers and in vitro under controlled conditions (Figure 6), both over a oneweek period and found significant differences between these measurements. Isolating the effect of material fatigue on pressure and stiffness revealed that most of the pressure loss takes place in the first four hours and that after $48 \mathrm{~h}$, the pressure stays stable for the materials under investigation. ${ }^{13}$

In vitro measurements allow pressure recordings over a longer period and in different ways. Figure 6 shows that recordings can be taken at different intervals and in Figure $7,{ }^{38}$ the recordings are presented of measurements during constant motion to mimic a walking pattern.

Therefore the recommendation of the ICC working group is that for in vitro testing of compression bandages and bandage systems, measurements are performed at specific intervals over a specific period, or e.g. to mimic a walking pattern over a certain period. As material fatigue starts immediately after the application and is further enforced by stiffness measurements, it

Table 3. Recommendations of the International Compression Club working group bandages for in vitro measurements of compression bandages and bandage systems.

\begin{tabular}{|c|c|}
\hline Topic & Recommendations \\
\hline Leg-shaped or cylinder & $\begin{array}{l}\text { It is recommended that measurements are performed on cylinders. } \\
\text { It is recommended that the friction between cylinder surface and bandaging } \\
\text { material should be reduced to the minimal (e.g. by using polished steel). }\end{array}$ \\
\hline Application method & $\begin{array}{l}\text { It is recommended that applications are performed as recommended in the } \\
\text { instructions for use. } \\
\text { It is recommended that applications should be controlled, automated and } \\
\text { reproducible. }\end{array}$ \\
\hline Stiffness & $\begin{array}{l}\text { It is recommended that stiffness measurements should be in line with } \\
\text { existing methods like the CEN method. } \\
\text { It is recommended that stiffness measured in vitro should not be named } \\
\text { static stiffness index; the term dynamic index used for stockings could be } \\
\text { used or a new term like strain index could be introduced. }\end{array}$ \\
\hline $\begin{array}{l}\text { Radius/circumference } \\
\text { of the cylinder }\end{array}$ & $\begin{array}{l}\text { It is recommended that for in vitro testing of compression bandages and } \\
\text { bandage systems, cylinders should be used with a radius of } 4 \mathrm{~cm} \\
\text { (circumference } 25.1 \mathrm{~cm} \text { ). }\end{array}$ \\
\hline Fatigue & $\begin{array}{l}\text { It is recommended that measurements are performed at specific intervals } \\
\text { over a specific period or e.g. to mimic a walking pattern over a certain period. } \\
\text { As material fatigue starts immediately after the application and is further } \\
\text { enforced by stiffness measurements, it is recommended to first perform the } \\
\text { measurement of pressure under tension before measuring the pressure in } \\
\text { the relaxed position. }\end{array}$ \\
\hline Pressure sensor & $\begin{array}{l}\text { It is recommended that for in vitro testing of compression bandages and } \\
\text { bandage systems, pressure should be recorded with a PicoPress }{ }^{\circledR} \text { transducer } \\
\text { (Microlab). } \\
\text { It is recommended to perform further research on the reproducibility of the } \\
\text { PicoPress }{ }^{\circledR} \text { (Microlab) device or alternative methods. }\end{array}$ \\
\hline
\end{tabular}


is also recommended to first perform the measurement of pressure under tension before measuring the pressure in the relaxed position.

\section{Pressure transducer}

In an ICC consensus document with recommendations for in vivo measurements, an overview is presented of key specifications of a pressure sensor. ${ }^{4}$ Partsch et al. compared three portable instruments and conclude that the best reproducibility and the highest degree of accuracy was achieved with the PicoPress ${ }^{\circledR}$ transducer (Microlab), which in addition also allows dynamic pressure tracing in connection with a software program and which may be left under a bandage for several days, is a reliable instrument for measuring the pressure under a compression device. ${ }^{39} \mathrm{Al}$ Khaburi reviewed available types of pressure measurement transducers to measure the interface pressure under compression products and states that these transducers differ in their core technology, physical dimensions, accuracy and their ability to provide

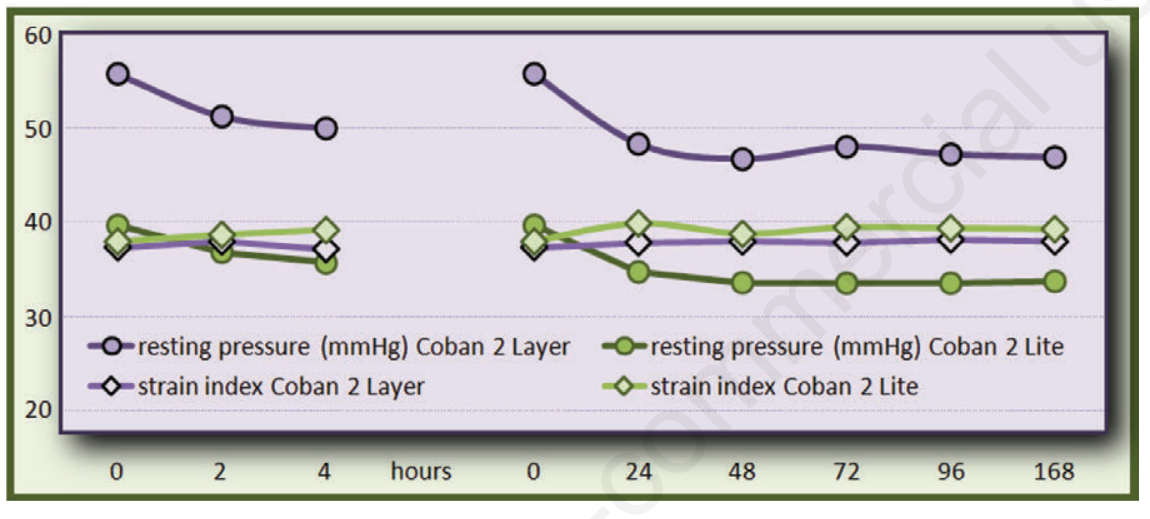

Figure 6. Measurement of pressure (in $\mathrm{mmHg}$ ) and strain index over a longer period.

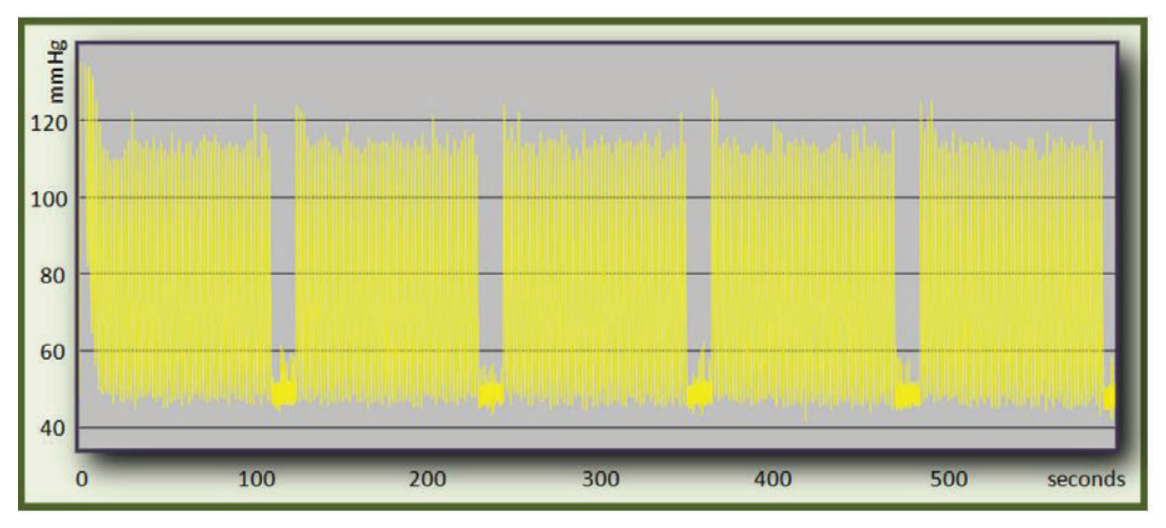

Figure 7. Measurement of pressure (in $\mathrm{mmHg}$ ) during motion mimicking a walking pattern. Modified with permission from Steinlechner and Bernat. ${ }^{38}$ dynamic measurements. He identified a total of more than thirty types that could be used. He performed a comprehensive analysis on different pressure transducers among which the PicoPress $^{\circledR}$ transducer (Microlab). One of the conclusions is that the PicoPress ${ }^{\circledR}$ (Microlab) sensor was found to have good accuracy in terms of low nonlinearity, and hysteresis errors but that it overestimates the pressure applied to it due to its physical dimensions. The usage of a correction factor for the pressures measured by PicoPress $^{\circledR}$ (Microlab) sensors could improve the reliability of their pressure readings. However, the author states that correction factors are calculated from the radius of curvature of the leg which is very difficult to determine within a clinical environment. ${ }^{28}$ As the recommended in vitro measurements in this article are performed on cylinders with the same radius, an accurate, reliable and repeatable overestimation does not play a major role and the suggested correction is not required. Based on these findings, the ICC working group rec- ommends that for in vitro testing of compression bandages and bandage systems, pressure should be recorded with a PicoPress ${ }^{\circledR}$ transducer (Microlab). Because of the reported overestimation of the pressure, it is recommended to perform further research on the reproducibility of the PicoPress ${ }^{\circledR}$ (Microlab) device or alternative methods.

\section{Next steps}

After the ICC working group bandages meeting in Copenhagen, a few members agreed to implement the recommendations to further optimize the in vitro measurement of compression bandages and bandaging systems. This work is still ongoing. In addition, the ICC working group bandages agreed to perform further research to investigate the relation between in vivo and in vitro measurements.

\section{Recommendations}

Recommendations of the ICC working group bandages for in vitro measurements of compression bandages and bandage systems are summarized in Table 3.

\section{Clinical relevance}

In vitro measurements of pressure and stiffness is a well known method used for the classification of medical elastic compression stockings. There are several classification systems in different part of the world, which have one thing in common, they are all based on the findings of in vitro measurements. ${ }^{11}$ For bandages or bandage systems that are used for compression therapy, there is no common language to describe the physical properties. There is only one classification system for bandages, which is based on force-elongation curves obtained in a laboratory. ${ }^{6,40}$ This system only provides pressure information on bandages used for so-called single component applications and uses light $(<20$ $\mathrm{mmHg}$ ), medium (21-30 mmHg), high (31-40 $\mathrm{mmHg}$ ) and extra high (41-60 mmHg) as pressure ranges. For single component bandages, the terms rigid or no-stretch $(0-10 \%)$, shortstretch (10-100\%) or long-stretch (>100\%) are most often used. These definitions are based on the percent elongation of the material after application of a force of $10 \mathrm{~N}$ per $\mathrm{cm}$ bandage width. ${ }^{1,6}$ Veraart et $a .^{2}$ and Thomas ${ }^{3}$ also described classification systems for single component compression bandages. However, many bandaging systems are commercially available for which these terms are not very useful. Most of the used materials have package inserts to describe how they are best used. A validated and reproducible method to investigate the preferred application method is not available yet. It is obvious that a standard for testing and classification of bandage systems is required. ${ }^{15}$ In an earlier ICC consensus document, the practical aspects of classifying compression bandages 
was presented. ${ }^{6}$ One of the conclusions was that future descriptions of compression bandages should include the sub-bandage pressure range as well as information on the stiffness of the final bandage. The development of a validated classification system is one of the objectives of the ICC working group bandages. This document presents the current status, recommendations and next steps of the development of these future descriptions. With such a descriptive system in place, specific information on the physical properties of bandages and bandaging systems can be provided on packaging and instructions for use, similar to the ones used for compression hosiery.

\section{References}

1. Deutsches Institut für Normung EV. DIN 61632 Verbandmittel, Idealbinden. Berlin, Wien, Zürich: Beuth Verlag; 1985.

2. Veraart JCJM, Neumann HAM. Interface pressure measurements underneath elastic and non-elastic bandages. Phlebology 1996;14:2-5.

3. Thomas S. Bandages and bandaging: the science behind the art. Care Sci Pract 1990;8:56-60.

4. Partsch H, Clark M, Bassez S, et al. Measurement of lower leg compression in vivo: recommendations for the performance of measurements of interface pressure and stiffness: a consensus statement. Dermatol Surg 2006;32:229-38.

5. Partsch H. The static stiffness index: a simple method to assess the elastic property of compression material in vivo. Dermatol Surg 2005;31:625-30.

6. Partsch H, Clark M, Mosti G, et al. Classification of compression bandages: practical aspects. Dermatol Surg 2008;34: 600-9.

7. Mosti G, Mattaliano V, Partsch H. Influence of different materials in multicomponent bandages on pressure and stiffness of the final bandage. Dermatol Surg 2008;34:631-9.

8. Schuren J, Bichel J. Sub-bandage dynamics: stiffness unravelled. Veins and Lymphatics 2013;2:e2.

9. Wertheim D, Melhuish J, Williams R, Harding K. Measurement of forces associated with compression therapy. Med Biol Eng Comput 1999;37:31-4.

10. Collier M, Schuren J. Ease of use and reproducibility of five compression systems. J Wound Care 2007;16: S8-10.

11. Van Geest AJ, Veraart JCJM, Nelemans P, Neumann HAM. The effect of medical elas- tic compression stockings with different slope values on edema measurements underneath three different types of stockings. Dermatol Surg 2000;26:244-7.

12. Neumann HAM. Compression therapy with medical elastic stockings for venous diseases. Dermatol Surg 1998;24:765-70.

13. Schuren J. Compression unravelled. Essen: Margreff Druck GmbH; 2011.

14. McCollum C. Extensible bandages should be dispensed with more information on performance. BMJ 1992;304:520-1.

15. Clark M. Compression bandages: principles and definitions. In: Calne $\mathrm{S}$, ed. EMWA Position Statement: understanding compression therapy. London: Medical Education Partnership LTD; 2003. pp 5-7.

16. Cornu-Thenard A, Benigni JP, Uhl JF. Terminology: resistance or stiffness for medical compression stockings? Veins and Lymphatics 2013;2:e4.

17. Clark M. What are the differences between different compression materials. J Wound Technol 2010;8:6-8.

18. Swallow RT. Hosiery testing apparatus. United States Patent Application 1979: US 4,137,763.

19. Wray GR, Vitols R, Tjon WDS, Baker JE. Measuring apparatus. UK Patent Application 1986: GB 2,168,156/A.

20. Pirlitescu M, Guidici D, Quaranta M, Bignotti R. A device for measuring that can be exerted by a hosiery article. European Patent Application 2001: EP 1, $118,851 / \mathrm{A} 2$.

21. Testud JL, Sennoune M, Prudhomme JP, Ouchene A. Device for measuring pressure points to be applied by a compressive orthotic device. United States Patent Application 2002: US 6,334,363/B1.

22. Melhuish J, Clark M, Harding KG, Williams RJ. The effect of compression bandage application technique upon measured sub-bandage pressures. Wounds 2005;17:243-6.

23. Partsch H, Partsch B, Braun W. Interface pressure and stiffness of ready made compression stockings: comparison of in vivo and in vitro measurements. J Vasc Surg 2006;44:809-14.

24. Rajendran S, Anand SC. Evaluation of pressure profile of bandages using mannequin leg. In: Anand SC, Kennedy JF, Miraftab M, Rajendran S, eds. Medical textiles and biomaterials for healthcare. Cambridge: Woodhead Publishing Ltd; 2006. pp 233-242.

25. Kuenzli D, Braun W, Ruettiger M. Apparatus for the testing of elastic textile leg garments. United States Patent Application 2007: US 0,012,120/A1.

26. Ghosh S, Mukhopadhyay A, Sikka M, Nagla
KS. Pressure mapping and performance of the compression bandage/garment for venous leg ulcer treatment. J Tissue Viability 2008;17: 82-94.

27. Wesp HJ, Oestreicher U, Jung H. Device for the determination of parameters particularly for therapeutic compression means on limbs. United States Patent Application 2009: US 0,215,016/A1.

28. Al Khaburi JAJ. Pressure mapping of medical compression bandages used for venous leg ulcer treatment. The University of Leeds, School of Mechanical Engineering; 2010.

29. Hirai M, Niimi K, Miyazaki K, et al. Development of a device to determine the stiffness of elastic garments and bandages. Phlebology 2011;26:285-91.

30. Kumar B, Das A, Alagirusamy R. Prediction of internal pressure profile of compression bandages using stress relaxation parameters. Biorheology 2012;49:1-13.

31. Hirai M, Partsch H. The mannequin-leg: a new instrument to assess stiffness of compression materials. Veins and Lymphatics 2013;2:e3.

32. Stolk R, van der Wegen-Franken CPM, Neumann HAM. A method for measuring the dynamic behaviour of medical compression hosiery during walking. Dermatol Surg 2004;30:729-36.

33. European Committee for Standardization (CEN). Non-active medical devices; working group 2ENV12718: European prestandard medical compression hosiery; CEN TC205. Brussels: CEN; 2001.

34. Hitschmann G. In vitro pressure and stiffness testing of compression bandages on a roll winder using different cylinders. Data on file. Neuss: 3M Deutschland $\mathrm{GmbH}$; 2013.

35. Tenman WG, Park KGM, Ruckley CV. Testing compression bandages. Phlebology 1988;3:55-61.

36. Partsch H. Compression therapy of venous ulcers: haemodynamic effects depend on interface pressure and stiffness. EWMA J 2006;6:16-20.

37. Das A, Kuma B, Mittal T, et al. Pressure profiling of compression bandages by a computerized instrument. Indian J Fibre Textile Res 2012;37:114-9.

38. Steinlechner E, Bernat V. In vitro compression model leg. Data on file. Rengsdorf: Lohmann \& Rauscher GmbH; 2012.

39. Partsch H, Mosti G. Comparison of three portable instruments to measure compression pressure. Int Angiol 2010; 29: 426-430.

40. British Standards Institution. The elastic properties of flat, non-adhesive, extensible fabric bandages. BS 705 1995. London: BSI; 1995. 